\title{
College Students' Positive Mentality Cultivation from the Perspective of Confucian Culture
}

\author{
Zhi Jing \\ Honors College, Nanjing Normal University, Nanjing, China \\ Email address: \\ 10729855@qq.com \\ To cite this article: \\ Zhi Jing. College Students' Positive Mentality Cultivation from the Perspective of Confucian Culture. American Journal of Applied \\ Psychology. Vol. 8, No. 4, 2019, pp. 72-76. doi: 10.11648/j.ajap.20190804.11
}

Received: July 9, 2019; Accepted: August 12, 2019; Published: August 20, 2019

\begin{abstract}
The problem of college students' mental health is ultimately a cultural issue and a question of values. The core of Confucian culture is ethics and values. Therefore, solving the mental health problems of college students also needs to return to the tradition. Starting from "knowledge and action", "righteousness and benefits", and "group-self relationship", we will revisit the teachings of Confucian philosophers at both ends, help guide college students to think seriously, cultivate a positive and enterprising attitude towards life, experience the dilemma of a balanced life, learn the wisdom of seeking harmony also respecting differences, and build a comparatively harmonious and healthy character. Contemporary college students are more confident. They are brave to express themselves, dare to love and hate, and never follow suit. The understanding of personal value emphasizes the perfection of individual personality and the freedom and independence of life. Therefore, it is of practical significance to make use of the nourishment of Chinese excellent Confucian culture, explore two ends of a thing, cultivate the value rationality of college students, help them gradually form positive psychological mechanism of optimistic attitude towards life, mature and stable interpersonal communication, natural development of physical and mental will mechanism, and relatively harmonious and perfect healthy personality.
\end{abstract}

Keywords: Confucian Culture, Knowledge and Action, Righteousness and Benefits, Group-self Relationship, Mental Health of College Students

\section{Introduction}

College age is a critical and sensitive period of a person's psychological development. College students' mental health has also been one of the social concerns. Psychoanalytic school holds that there are various personal reasons for the emergence of psychological problems, but they are essentially from the influence of the cultural environment of a certain society on individuals. Compared with the past, there are three backgrounds that cannot be ignored when we study the mental health problems of contemporary college students. First, college students have generally undergone more intensive exam-oriented training nowadays. Although the gross enrollment rate of universities has increased dramatically in recent years, the pressure of college entrance examination has not decreased but risen, and parents' anxiety has become more and more intense. [1] Almost every college student has undergone many years of intensive, dense and refined repetitive exam-oriented training and rigorous daily life management. Second, the majority of college students are only child in their home. In the process of growing up, they are cared for and lack the ability of self-management and control. They are accustomed to the fact that the more parents take place of them in their own responsible things, the more dependent they are on their families, and the slower they adapt to the new environment. Because they have long been the focus of family attention, they are calm and self-righteous to the care from their parents and relatives, and they lack communication skills when meeting different views, and easily conflict with others, forming a psychological crisis. Third, the popularity of the Internet has weakened the sense of reality of contemporary college students. For some college students, the Internet exaggerates their knowledge and abilities infinitely, but they cannot feel their own value in the real world, and often have a feeling that is incompatible with reality.

In practice, mental health educators in Colleges and universities generally try to solve problems by using western 
psychological theories and methods, and have made remarkable achievements. However, theories from the west can hardly fully explain the problems in China, and psychological counseling methods from the West can hardly eradicate the mental health problems of contemporary college students. Mental health is a problem of personality health on the surface, but in fact it is a problem of culture, especially of values. [2] The core of Chinese traditional Confucian culture is ethics and values. Therefore, to solve the mental health problems of College students, we need to return to the origin, return to the tradition, and find a localized solution. The report of the Nineteenth National Congress of the Communist Party of China requires us to "dig deeply into the ideological concepts, humanistic spirit and moral norms contained in the excellent traditional Chinese culture, inherit and innovate in line with the requirements of the times, so that the Chinese culture can show its permanent charm and style of the times." Although today's society is quite different from the era in which the sages lived, the problems encountered in the traditional society will recur in one way or another in today's society. So "tradition is not something that has disappeared in history, not just sleeping in the relics of written literature, not something outside of us as modern people, but something that has been accumulated and passed down in history and acquired its own prescriptions through the restriction and domination of modern people. In this sense, understanding tradition is also our modern self-realization." [3] Today's college students are confronted with the problems of life significance and ideal value, morality and utility, moral value and material desire, personal interests and overall interests, which have also troubled our sages. Only in this way can there be continuous debates such as "the debate of knowledge and action", "the debate of righteousness and benefit", "the debate of group and self". Confucius put forward the idea of "exploring the two sides of a things exhaustingly" (The Analects of Confucius Zihan). That is to say, we have to inquire into the two opposing aspects of things, so as to make them understand by exhausting the whole picture. Reviewing the wise expositions of Confucian philosophers and gaining new enlightenment will help us find new ways to deal with practical problems and challenges. [4]

\section{Guiding College Students to Think Seriously and Cultivating Positive and Enterprising Attitude Towards Life}

Chinese traditional culture expresses the relationship between knowledge and practice as the relationship between knowledge and action. The ancient philosophers had different emphasis on "knowledge" and "action". As early as Shangshu, there was the expression of "knowing is not difficult, but doing is difficult". The Doctrine of the Mean puts forward the idea: Study extensively; Reflect carefully; Discriminate clearly; Practice earnestly. Zhuxi discussed the problem from the two aspects: order and importance. He proposed the idea: knowledge is before action; knowledge is more importance than action; and knowledge and action should work at the same time. Wang Yangming put forward and demonstrated "the unity of knowledge and action". From the perspective of moral conscience, he profoundly revealed that the unity of "knowledge" and "action" is the unity of moral consciousness and moral practice. Knowing is the idea of doing, and doing is the effort of knowing; knowing is the beginning of doing, and doing is the accomplishment of knowing." [5] Although the sages mainly understood the relationship between "knowledge" and "action" from the ethical point of view, and their understanding was not consistent, but they all emphasized the combination of the two. "Knowledge" must ultimately be implemented into "action". Therefore, we can also understand that the essence of Confucian philosophy of knowledge and action is "the unity of knowledge and action".

For contemporary college students, learning to inherit the principle of "unity of knowledge and action" has a very realistic pertinence. Years of intensive exam-oriented training and the popularity of virtual world have resulted in the "separation of knowledge from practice" of college students to a certain extent. Under the guidance of exam-oriented, learning motivation is generally utilitarian. The principle becomes that the knowledge conducive to raising grades and pursuing a higher school should be paid attention to. The purpose of "knowledge" is only to master knowledge points to cope with the exam and get high marks. The influence of this "separation of knowledge and action" is manifold. First, learning motivation is obviously weakened. Second, there is a lack of clear career planning, ambiguous goals and courage to move forward. The third is to know virtue but not to do it. Speaking of one set; doing another set. there is a serious disconnection between cognition and practice.

Therefore, today's college students need to seriously consider the relationship between "knowledge" and "action" and practice the principle of "the unity of knowledge and action ". First of all, we should make great ambitions and do small things. Today's college students should take an active part in social practice, establish correct value orientation in rich practice, link their aspirations to struggle with the future and destiny of the nation, closely link their personal learning progress with the prosperity of the nation, and lead the aggressive people with noble life goals. Only in this way can we fundamentally solve the puzzle of "why to learn". At the same time, through the practice of training to understand "easy to know, difficult to do". "A man needs to grind on things before he can stand, before he can be calm and still, and when he moves, he can be fixed." [6] Although "ambition" is important, we must be down-to-earth, learn to understand ourselves correctly from the University campus, learn to plan and manage our career, learn to grow up in setbacks, learn to break down big goals into a number of small goals, and implement them into practical actions at each stage, and constantly cultivate perseverance and hardworking spirit. In addition, we should also understand that "knowing but not doing is unknown". It is necessary to guide college students to 
take more actions and stick to them in their daily life. " Do not fail to do good even if it's small; do not engage in evil even if it's small. " Start with every little thing around you and gather the positive energy to promote social progress with practical actions. In addition, from the perspective of University educators, it is also necessary to further increase the opportunities for college students to participate in social practice, not only to impart theoretical knowledge and Book knowledge, but also to cultivate the practical ability of College students, guide them to build up their confidence in solving problems with their professional knowledge, and form an open mind that dares to accept new ideas and an enterprising mind that dares to seek solutions. [7]

\section{Guiding College Students to Think Seriously About the Relationship Between Righteousness and Interests}

"Righteousness" belongs to the category of spiritual value, which aims at judging whether people's behavior conforms to moral norms. "Benefits" belongs to the category of utilitarian value, aiming at measuring people's sense of material gain. The relationship between righteousness and benefits is a basic problem that runs through Chinese traditional culture. "All things under heaven are just for the sake of righteousness and benefit. [8] Under the condition of socialist market economy, economic benefits are the core of resource allocation, and the pursuit of personal interests is the basic driving force for people to engage in economic activities. Reasonable pursuit of personal interests helps college students to cultivate independent personality and self-reliance. But paying too much attention to interests and exchanging everything equally is also prone to bad behavior such as profit-seeking egoism and utilitarianism. Therefore, guiding college students to review the ancient precepts, learn a lot of discussions about the relationship between righteousness and benefit from the past generations, analyze and differentiate the ideological context and historical and cultural background of different views, and draw on the positive and reasonable factors, are conducive to helping college students to build a balanced relationship between righteousness and benefit in their personal value system, in order to establish a scientific concept of righteousness and interests consistent with the core socialist values, and avoid gains and losses in the face of interests.

On the one hand, college students should be guided to correctly view their personal gains and losses, with great significance rather than small benefits. Generally speaking, after the Western Han Dynasty, the Confucian theory of emphasizing righteousness and neglecting benefit was in the dominant position. Emphasizing righteousness over benefit is the value pursuit that sages have always advocated, and is also the basic value orientation of Chinese excellent traditional culture. College students are the hope and future of the motherland, shouldering the historic task of building the motherland and realizing socialist modernization. Since the reform and opening up, in the tide of market economy, people's outlook on righteousness and interests has been greatly impacted, and the values of college students have also undergone significant changes. [9] Because the thought of college students is not mature and stable enough, their value orientation is influenced not only by the traditional Chinese view of justice and benefit, but also by the interference of money worship and extreme individualism. In the current complex environment of pluralistic thinking, pluralistic value and pluralistic public opinion, it is more important to guide college students to correctly handle the relationship between righteousness and interest, to consider individual interests in the context of national, national and collective interests, so that they can correctly use what they know and learn, shoulder the responsibility of the times and fully display their self-worth. Otherwise, the interests of individuals are all water without origin, wood without roots, and there is no way to talk about it.

On the other hand, we should guide college students to correctly deal with the balance of material interests and spiritual values and learn to "benefit from righteousness". Man must live on a certain material basis, especially under the conditions of market economy. If one-sided emphasis is laid on righteousness while neglecting benefits and completely abandon his own interests, he will inevitably go to another extreme. Dong Zhongshu advocated "having both righteousness and benefit". "Heaven begets man and makes him righteous and seek benefits. Having benefits provides us physical strength, while having righteousness provides us mental strength. You can't be happy without righteousness; you can't feel comfortable without benefit. Righteousness is for nourishing the heart while benefit is for nourishing the body. [10] On the premise of giving consideration to both individual, collective and society, taking into account both demand and dedication, college students should be encouraged to venture and compete bravely on the basis of their learning strengths, to pursue personal interests and happiness through legal means, so as to realize their self-worth and to increase wealth and contribute to society. Only in this way can we mobilize the creativity of college students and the enthusiasm of labor, and promote the sustained and healthy development of social economy. In addition, on the basis of a correct view of the relationship between righteousness and interests, we should learn to maintain a peaceful mind and constantly improve our self-cultivation. Thus we can further understand the life realm of "Benefit without expense, work without complaint, desire without greed" (Analects of Confucius Yao Yue).

\section{Guiding College Students to Think Seriously About the Relations Between Group and Self}

The group-ego relationship explores the relationship between individual and collective (state), individual and others. The debate between self and group originated from 
Confucius. Confucius said, It is impossible to associate with birds and beasts, as if they were the same with us. If I associate not with these people-with mankind-with whom shall I associate? (The Analects of Confucius, Weizi) "The Superior Man strives but does not wrangle." (The Analects of Confucius, Wei Linggong) Since Confucius, Confucianism has focused on the group order, emphasizing the reconstruction of rites and music to optimize the group-self relationship. However, Confucianism does not advocate that individuals blindly obey groups and erase human personality. Confucius' thought of "seeking harmony but respecting difference" fully embodies the wisdom of the sages in dealing with the relationship between group and self. In the view of modern scholars, "a culture must maintain the stability of liquidity, in order to cope with the ever-changing environment of the outside world, in order to survive. There are only two possible ways to achieve this mobility in a well-regulated society. One is that there is already a possibility of adaptation in the norms, allowing individuals to have mechanisms for questioning and introspecting the norms. Secondly, in the process of implementation, individuals are allowed to have a higher degree of freedom in interpreting and implementing norms. [11] Thus it can be seen that the wisdom of "seeking harmony but respecting difference" is one of the keys to the continuity of Chinese traditional culture. For today's College students, because most of them are only child in their family, they are used to self-centered thinking when dealing with the relationship between individuals and collectives, individuals and others. Once their demands are not met, they are prone to hostility, anger and other emotions. Therefore, learning the wisdom of "seeking harmony but respecting difference" helps to establish good interpersonal relationships. [12]

From the perspective of harmony, first of all, we should actively integrate into the collective, learn to cooperate and learn to compromise. Individual behavior is by no means a small model carved from a large model of culture, history and society. Individuals as "people" have their own needs, and their behavior must also meet the needs of individuals. [13] Therefore, it should be a compromise result of adjusting the responsibility of "individual" in "society" and meeting individual needs. Everyone's opinions about their affairs, people and the world are reflecting such a well-coordinated outcome. Secondly, when dealing with others, we should learn to respect and tolerance. Respect and accommodate the differences of each individual, communicate with each other more, think differently more, resolve differences actively, and avoid the extreme situation of "disagree with each other, draws sword against each other". Thirdly, we should step down from the Internet, develop more real-world contacts, actively broaden the circle of communication, and recognize ourselves more objectively in communication. At the same time, adhering to the ancient motto of "when three people walk together there must one who can be my teacher." We should see more advantages, learn more advantages, learn from each other's strengths and make up for each other's weaknesses, so as to further enhance the sense of identity between people in real life. [14]
From the perspective of "different", we should not only avoid being different, but also have the attitude to not be the same with others easily. Contemporary college students are more confident. They are brave to express themselves, dare to love and hate, and never follow suit. The understanding of personal value emphasizes the perfection of individual personality and the freedom and independence of life. Therefore, "avoiding being different" is to encourage college students to develop good habits of independent thinking, constantly enhance the awareness of innovation and practice, without violating public order and good customs premise, boldly maintain their true face, fully display their personality, live a brilliant life with distinct personality.

\section{Conclusion}

Not easily being same with others is to adhere to principle in interpersonal communication. Some college students are more emotional in interpersonal communication. They will help their friends with similar personality without principle, and they will often trouble students who have bad relationships. "A noble person will be willingly to help others to success and to avoid any troubles." (The Analects of Confucius, Yanyuan). Confucius always advocated "gentleman's acquaintance". To be a man, we must stress principles and be clear about right and wrong. "Harmony" is not an unprincipled group of harmony, let alone unconditional tolerance. Otherwise, it is what Confucius called "villains" and "hypocrites". [15]

\section{References}

[1] Ji Xinbo, Wang Yonghong, Zhao Chunhui. Investigation on Psychological Adaptability and Satisfaction and their Psychological Health Education Needs among College Students [J]. Chinese Journal of Health Education, 2019, 35 (1): 92-95.

[2] Zhao Shan, Li Yan. Constructing the Chinese Model of the Main Channel Education of College Students' Mental Health [J]. Chinese Higher Education, 2017 (17): 61-62.

[3] Zhang Chuanqian, Wang Chuanfa. Righteousness and Benefits [M]. Nanjing: Nanjing University Press, 1997: 230.

[4] Chen Weiping. Traditional and Modern Release Positive Energy in Complementarity [N]. Wen Wei po, 2014-6-10 (12).

[5] Wang Yangming, notes by Deng Aimin. Notes to Biographies [M]. Shanghai: Shanghai Ancient Books Publishing House, 2012: 11 .

[6] Wang Yangming, notes by Deng Aimin. Notes to Biographies [M]. Shanghai: Shanghai Ancient Books Publishing House, 2012: 28 .

[7] Cheng Xiaoliang, Zhang Yongfang. College Students'Learning and Quality Improvement Strategies in the Big Data Era [J]. Modern Education Management, 2016 (2): 63-65.

[8] Cheng Hao, Cheng Yi. The Anthology of Two-Cheng [M]. Beijing: Zhong Hua Book Company, 2004: 114. 
[9] Xue Sainan. The Relation between Humanistic Care and Ideological and Political Education [J]. Modern Education Management, 2016 (6): 113-118.

[10] Dong Zhongshu. Chun Qiu Fan Lu [M]. Shanghai: Shanghai Ancient Books Publishing House, 1989: 54.

[11] Mei Zhongfang. How to Study Chinese [M]. Chongqing: Chongqing University Press, 2009: 120.

[12] Xie Xiluan. Personality Cultivation of College Students in Ideological and Political Education [J]. Education and Vocation, 2016 (11): 44-46.
[13] Mei Zhongfang. How to Study Chinese [M]. Chongqing: Chongqing University Press, 2009: 40.

[14] Shi Ruibao. Approaches to Social Work Intervention in College Students' Mental Health Education [J]. Chinses Adult Education, 2016 (11): 49-52.

[15] Ding Zhengrong, Hu Quanyu. On the Rational Application of Confucian Culture in Ideological and Political Education of College Students [J]. The Party Building and Ideological Education in Schools, 2019 (10): 78-80. 